\title{
Wasteland Beautiful: o estatuto ontológico da imagem nos mundos tridimensionais dos games
}

\section{Beautiful Wasteland: the ontological structure of the image in three- dimensional worlds of games}

\author{
Luís Carlos Petry \\ Doutor em Comunicação e Semiótica pela PUCS. Professor e Pesquisador no Programa \\ de Pós-graduação em Tecnologias da Inteligência e Design Digital da PUCSP. Formação \\ em Liceu de Artes, Filosofia e em Psicanálise pelo CEF. \\ petry@pucsp.br
}

\section{Thiago Sanches Costa}

Mestre em Tecnologias da Inteligência e Design Digital (PUCSP). Bacharel em Comunicação Social, Jornalismo pela PUCSP. Professor no Curso de Comunicação Social da FACOM-FAAP.

thicosta@gmail.com.

\section{Alexandre Vieira da Silva}

Mestrando em Tecnologias da Inteligência e Design Digital (PUCSP). Formado em Design Digital pela Universidade Anhembi Morumbi e Especialista em computação Gráfica pelo SENAC-SP Professor no Curso de Especialização em Games (SENAC-SP). alexandre.vsilva@sp.senac.br.

\section{Gabriel Cavalcanti Marques}

Mestrando em Tecnologias da Inteligência e Design Digital (PUCSP). Graduado em Jogos Digitais pela FMU.

arzael_wolf@hotmail.com

\section{Marcel Casarini}

Mestrando em Tecnologias da Inteligência e Design Digital (PUCSP). Bacharel em Arquitetura e Urbanismo pela Universidade Presbiteriana Mackenzie.

marcelcasarini@gmail.com

\begin{abstract}
The paper presents the concept of the digital image in games as the result of an artistic process, digital and personified in the figure of the craftsman, which focuses its activity on a make-believe. The article is located within a proposed phenomenological thought that seeks to show the ontological structure that underlies the work with digital images and drawing / painting / color / dash / form in target quality, considering the production of games. Shows that the ontological contexts outlined are present unintentionally in public displays of development teams, analyzing and illustrating two exemplary examples in which the game chasing a homoiosis produced in relation to digital and historical tradition. Culminates in the defense of a research on the artistic
\end{abstract}


production in games coupled with production processes and understanding games as an art form that speaks to today's man.

\section{Keywords}

Picture, digital, game, paint, topophilosophy.

\section{INTRODUÇÃo}

Este texto trata da imagem digital, da beleza trágica e surpreendente que ela pode atingir nas mãos dos artistas de jogos e sua correspondente implicação ontológica. Após os debates americanos sobre a possibilidade dos games serem ou não considerados como obras de arte nos EUA, a National Endowment for the Arts (NEA), em 2011, promulgou posição oficial ${ }^{24}$ dizendo que os games se constituíam em um legítimo objeto artístico e, assim, também poderiam se beneficiar das leis americanas de fomento à cultura e artes (Funk, 2011).

Trata-se de um longo e penoso debate que envolveu, não somente a comunidade de fãs, mas também desenvolvedores e artistas digitais, pesquisadores e críticos de arte, indústria, opositores, entre outros e foi amplamente coberto pelos principais veículos de discussão e debates da área ${ }^{25}$. Por exemplo, Bateman (2011) nos informa que o renomado crítico de cinema Roger Ebert havia escrito em seu Blog, em Abril de 2012, que simplesmente os videogames não eram arte, que eles jamais poderiam ser considerados arte. Bateman nos indica que o colocado por Bert atualisa uma ideia de que não seria verdade o fato de que um game é uma obra de arte, o que, dentre outros aspectos seria colocar em evidência uma pergunta ontológica.

Se os jogos são ou não obras de arte é uma questão que certamente merece

\footnotetext{
${ }^{24}$ A publicação oficial da NEA pode ser conhecida em: http://arts.gov/grants/apply/AIMpresentation.html. Após a promulgação da NEA o mundo segue o seu curso e toda a comunidade que trabalha com a imagem digital recebeu um estímulo a mais para continuar produzindo. ${ }^{25} \mathrm{O}$ site de jornalistas especializados Icontric, por exemplo, realizou matéria sobre o tema. Além disso, desde 2009, David Fox e John Sharp discutiam no portal gamasutra a questão: pode um game ser considerado uma obra de arte?
} 
ser perseguida ${ }^{26}$ e todo um espaço de discussão deveria ser reservado para tal, análise que o escopo do presente artigo não permite. Entretanto, o que nos fez tocar nela é o fato de que o objeto de interesse de nosso artigo, a imagem (digital), está fortemente presente nos games e, a imagem enquanto tal é objeto de uma discussão de disciplinas como estética e ontologia. Ora, podemos considerar as imagens digitais, aquelas presentes nas associações na Web dedicadas à publicação de trabalhos (como Deviant art e Renderosity) como obras de arte? O que irá diferenciar os trabalhos publicados em tais comunidades digitais dos publicados em galerias e museus virtuais como, por exemplo, os do The Art Renewal Center ${ }^{27}$ ? Colocar as questões se torna muito mais importante do que fornecer as suas respostas. Talvez porque elas chamam a nossa atenção para a necessidade de pensarmos mais profunda e detalhadamente os contextos nos quais se fundam as nossas práticas e o que buscamos pensar aqui, sem pretender qualquer caráter de definitivo, é justamente a imagem digital, em seu esplendor e potência ontológicos.

\section{ARTE E CONHECIMENTO: A tOPOLOGIA PLÁstica dO CONCEITO-IMAGEM}

Produzir uma imagem é produzir um mundo que é dado a ver ao outro. Produzir uma imagem é plasmar um corpo colorífico no toque, traço e forma do pensado que se dá no fazer da obra. Obra, seu fazimento e fazedor andam juntos e são indissociáveis. Reunimos no presente artigo as expressões que os designam: seu artífice e seu atelier no qual obra e o espaço do corpo plástico colorífico que é dado ao ver e ao sentir do homem.

\subsection{O ARTÍFICE DA IMAGEM NA OFICINA DIGITAL}

Sennett (2009) apresenta o conceito de artífice e o aplica em uma discussão sobre as relações cooperativas entre o pensar e o fazer, entre cérebro e mão. A oficina do artífice se constituiria em um espaço de produção ontologicamente privilegiado. Tomando como modelo de sua visada, a oficina renascentista e a transformação do artesão em artista, poderia ser elucidativa para entendermos os atuais ambientes de trabalho em games que funcionam ao modo de oficinas (Sennett, 2009: 67-96).

\footnotetext{
${ }^{26}$ Recomendamos, por exemplo, a leitura do texto de Bateman (2011). Imaginary games, sobre esse aspecto.

${ }^{27} \mathrm{O}$ endereço Web do The Art Renewal Center é http://www.artrenewal.org
} 
Para pensarmos a imagem digital, o conceito de artífice é fundamental. Ele nasce de um desafio lançado pelo filósofo Richard Foley que, em um momento de impasse reflexivo de Sennet Ihe perguntou: Qual intuição que o orienta? E Sennett respondeu: fazer é pensar. Da interrogação do colega nasceu um programa de pesquisa, o qual produziu uma problematização que chegou a nós pelo conceito de artífice.

Pensamentos e sentimentos estão inclusos no processo do fazer. No fazer, o homem pensa com os materiais, pensa e sente em meio às coisas, enfrentando o dilema sempre problemático que se abriga no fazer, entre o como, o quê, o porquê e, também, o para quê ou quem. Sennett nos diz que para que possamos aprender com as coisas precisamos aprender a apreciar as suas qualidades. Para apreciarmos um desenho ou uma pintura, anteriormente temos de aprender a apreciar o traço, a hachura, a cor e a pincelada. No centro da questão do artífice, Sennett encontra a habilidade artesanal, um conceito que até então parecia estar esquecido e soterrado pela ação da técnica, o qual ele irá resgatar, do renascimento aos estúdios dos modeladores tridimensionais e dos pintores digitais.

A utilização de ferramentas, que são percebidas como imperfeitas ou incompletas, conduzem a ação do artífice no sentido do desenvolvimento de sua imaginação e das capacidades necessárias para suprir as deficiências encontradas e, ainda, no caminho de aperfeiçoar seus utensílios ${ }^{28}$. Dentro desse contexto é que assistimos ao florescimento de inúmeras competências e habilidades, as quais sempre empurram os sujeitos na direção do desenvolvimento de suas atividades com uma maior qualidade. Para o filósofo, motivação é mais importante do que o talento: o desejo de qualidade do artífice cria um perigo motivacional: a obsessão de fazer com que as coisas saiam à perfeição pode deformar a própria obra (Sennett, 2009: 21). Tendemos mais a fracassar por não alcançarmos organizar adequadamente a nossa obsessão do que pela simples falta de habilidade. Nesse sentido, o conceito indica uma renitente busca pela qualidade que anima o artífice, na qual ele tende a retornar sobre seu objeto e compreender seus processos com ele e no fazer dele.

No espaço aberto da oficina o artífice se transforma em artista. Em termos práticos, não podemos pensar em obra, em imagem produzida, sem pensarmos na artesania como a sua base estrutural: a ideia de uma pintura

\footnotetext{
${ }^{28}$ Heidegger (2008) nos diz que o ser-utensílio do utensílio consiste por certo em sua serventia.
} 
não é uma pintura. O pensamento caminha pari passu com a fenomenologia, a qual faz ver que a obra de arte se funda e se organiza por meio de um construir (Heidegger, 1974, 2008, 2010 \& 2012).

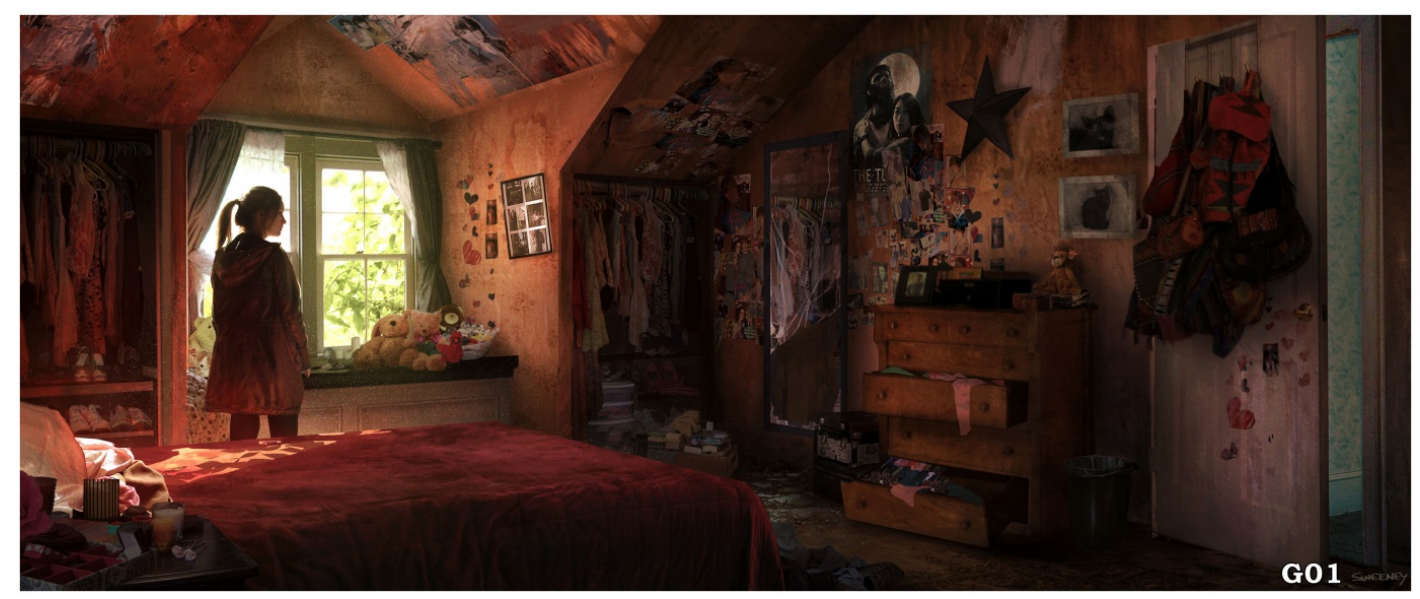

G01: A cor, o traço e a forma na plástica da imagem

Estamos habituados a discutir a imagem a partir do suporte no qual ela é produzida ou exibida: papel, tela, madeira, vidro, écran do computador, projetor... Ao fazermos isso, nos fixamos no meio-suporte ou no meioexibição, sua portabilidade e exibição, entendendo neles a sua natureza. No entanto o papel, a tela, a madeira, o vidro, o écran do computador não são a imagem. Eles são simples suportes para a imagem. Imagem é cor, traço, pincelada e forma, organizados pela ação do artífice que produz demoradamente a imagem, eles parecem que desaparecem de nossa atenção, pois se mesclam uns aos outros e se fusionam no que denominamos uma imagem. Está ela ali, pronta, diante de nós e, ao invés de a percebermos na potência de sua cor, de seus traços e pinceladas e a profusão de formas e massas plásticas que ela engendra, nós tendemos a conformá-la em um suporte 29 .

Jacques Lacan (1901-1981), em seus Escritos (1998), ao abordar a questão da subversão do sujeito e a dialética do desejo, irá dizer que o significante de uma falta no campo do grande Outro é o traço que traça o círculo, sem aí poder contar. Ora, ao traçarmos um círculo, o realizamos pelo traçar do traço que, em sua conclusão, não se faz mais presente. De certo modo, o dizer de Lacan poderia funcionar como uma metáfora para o processo de produção da imagem por meio do processo indicado por nós acima: traçamos, fusionamos cores,

\footnotetext{
${ }^{29}$ Como muito bem diz Murray, (2003:40): "Toda tecnologia bem sucedida para contar histórias torna-se transparente: deixamos de ter consciência do meio e não enxergamos mais a impressão ou filme, mas apenas o poder da própria história".
} 
produzimos formas e, no final, o registro plástico se apresenta como a nossa imagem.

Quando timidamente pensamos e percebemos o estatuto da imagem a partir de seus componentes fundamentais (cor, traço e forma), visualizamos a proximidade que sua produção pode ter com a ideia do artífice de Sennett. Ela, a imagem produzida pela mão do homem, somente pode advir à sua apresentação, por intermédio de sucessivas e reiteradas ações, nas quais cor, traço e forma são gestados no horizonte da qualidade. Ainda mais, quando, para Kandinsky (2001), a angústia da forma deve, enquanto objeto se fundir com a pintura na promoção do desaparecimento do objeto, a alma deve revelar-se por meio das massas de cores na simplicidade do ver a imagem.

Ora, trata-se da operação do jogo continuado da produção da imagem que, a partir de um olhar fenomenológico, se constitui em uma estrutura prática que tem como horizonte de sua ação o fazer emergir uma experiência estética, a qual enlaça em um jogo cooperativo o produzir-ver, tanto do artífice da imagem como daquele que a contempla. Quando Schiller (1759-1805) poetiza o jogo da arte, a partir do pêndulo celestial, entre razão e sensibilidade, é justamente esse vaivém do produzir-ver que se insinua (Petry, 2010).

\subsection{ONTOLOGIA E IMAGEM DIGITAL}

Trata-se aqui, na verdade, da ação de uma estrutura prática. Somos cativos dos suportes e daqueles que organizam seus discursos ao redor deles; dos críticos e dos que tecem as opiniões do bom gosto. Algumas observações de Heidegger (2008), ao abrir com um discurso uma exposição do escultor Bernhard Heilliger (19915-1995), podem nos ajudar a situar nossa visada. Ele nos diz que, na época da arte grega, não havia algo como uma literatura sobre arte ou mesmo críticos de arte. A arquitetura, a escultura e a pintura dos mestres falavam por si mesmas. Elas mostravam per si e, situavam os homens em seu espaço e, a partir delas somente, os homens recebiam a sua determinação. Na simplicidade do dar-se a ver, do mostrar, elas colocavam questões ao homem no espaço aberto da disposição dos Deuses e do mundo. Assim como as obras dos escultores e pintores não necessitavam de nenhuma galeria para serem consideradas (e de alguém que as sancionassem), de igual modo elas prescindiam de uma documenta. Entretanto, hoje, no centro da era da técnica, as coisas não se dão mais desse modo. Como animais presos em 
correntes, temos hoje, a todo o momento, de testemunhar acerca de nossa validade e serventia a nossos guardiões ${ }^{30}$.

Porém, o que a observação do filósofo nos indica é algo fundamental. Ela aponta para o fato de que o mais essencial no artista que produz não se encontra fora dele mesmo, mas sim em sua própria e reservada atividade. É o que se pode apreender no domínio da ação do artífice, a qual, como já observado, se funda e se organiza por meio de um construir que se dá ontologicamente.

Ora, aprendemos com Stein (2011) que no âmbito prático, sempre partimos de uma ontologia, ainda que atencionada. Não cabe ao artífice discursar sobre o seu fazer, aliás, se assim o fizer, nada fará senão discurso. A breve e angustiada carreira de presbítero e seus discursos inflados é interrompida para Van Gogh (1853-1890), quando em meio aos pobres mineiros, ele pinta Os comedores de batata (1885) (Haziot, 2010). Isso não significa que o artífice não pense. Ao contrário, pensa e pensa profundamente o objeto de sua atividade em constante movimento e transmutação. Como nos diz Sennet, ele é o sujeito humano no qual o fazer é o pensar que se dá silenciosamente no processo do próprio fazimento, no qual constrói sua própria historicidade no rastro de sua produção. A ele cabe o obrar demoradamente na visada da qualidade.

Esse obrar da obra, que é imagem, consiste em um fazer que se dá contemporaneamente com um pensar, que pode revelar-se em sua estrutura topológica, tal como uma fita de Moebius que, na fluidez de seu percurso, torcendo-se sobre si mesmo, irmana-o em um fazer-pensar (Petry, 2003: 65). Visualizamos, na estrutura topológica, a descrição de um processo que tende a escapar, como o já observado na metáfora do traço que traça o círculo sem aí poder contar. Ao final, com o círculo traçado, o seu traçar histórico é abandonado ao esquecimento que a presentificação do círculo acabado presentifica. O traçar resta então lançado ao mistério oculto da produção, sem poder vir à tona, esquecido ou desconsiderado, muitas vezes, por aquele que contempla a imagem diante de si. Põe-se aqui o mistério da arte pelo fazer do artista:

\footnotetext{
${ }^{30}$ Diz respeito a um mundo no qual o certificado e a burocracia valem mais do que o próprio pensamento. Livros inteiros compondo páginas sem sentido podem contar na burocracia acadêmica, desde que tenham o seu próprio registro de publicação.
} 
O maravilhoso e misterioso da arte é que esta pretensão determinada não é, contudo, uma camisa de força para nosso ânimo, mas antes precisamente o que abre um campo de jogo para a liberdade no desenvolvimento de nossa capacidade de conhecer (Gadamer, 1998: 86).

Para Goodman (2006), o olhar chega sempre atrasado ao seu trabalho. Isso significa que nenhum olhar é inocente (Gombrich, 2007) ${ }^{31}$, pois o olhar atual, carregado do anterior, tem ainda de lidar com a necessidade e o preconceito. Nesse sentido, toda imagem possui uma estrutura cognitiva para o sujeito do olhar, mesmo quando esta para alguém nada signifique. O apelo cognitivo da imagem nos coloca na posição de observarmos que ela está sempre, de um modo ou de outro, relacionada com a nossa capacidade de conhecer e dar sentido ao todo de nossa experiência. Nos games, esse apelo funda um mundo em seus três eixos fundamentais, para o olhar (Petry, 2009) e o navegar (Manovich, 2005). Ora, o apelo cognitivo se encaminha da imagem ao seu observador e, para os estudiosos da semiótica instaura uma estética da recepção e uma estrutura cooperativa de campos semânticos que se conectam e entrelaçam $(E c 0,2000)^{32}$.

Ao pensar a obra de arte, Heidegger (2010) discute um momento altamente significativo, o qual pode ser considerado como preliminar para os nossos encaminhamentos. Ele ocorre quando o filósofo pensa uma pintura de Van Gogh (1853-1890), Um par de sapatos (1886) [P01], um óleo sobre tela que se encontra no Museu Van Gogh, em Amsterdam, na Holanda.

\footnotetext{
${ }^{31}$ Partindo do princípio de que o objeto está na leitura de quem o vê, Gombrich (2007: 64) discute que um artista pode classificar um borrão como algo e a partir dessa classificação, reforçar os traços para criar um significado mais claro. Esse tipo de ilusão, tal como observar formas familiares nas nuvens no céu, dá-se devido a nossa incapacidade de rodear a imagem que temos na frente de nós, tendo assim um ponto de vista estacionário. Logo não tendo a compreensão total da imagem a nossa frente, projetamos nela uma expectativa de significado, criando assim objetos a partir de borrões por exemplo.

${ }^{32}$ Eco é aqui o grande autor, principalmente quando desenvolve progressivamente o seu tratado geral de semiótica, desde a publicação de $A$ estrutura ausente, passando pelas Formas do conteúdo e, não finalizando, mas reescrevendo tudo, no Tratado Geral de Semiótica. Também do lado da imagem, temos Jacques Aumont (2005) como um dos pesquisadores que se dedicam exaustivamente ao tema, explorando o conceito e objeto imagem a partir do olho como órgão psicofisiológico, a partir do olhar que olha a imagem, como dispositivo real e simbólico e, o sentido da imagem considerada em si mesma. Outro é André Bazin (1918-1958) que explorou as diferenças entre cinema e pintura, na ideia de cinema impuro (ver Cruz, 2007 e Schlögl, 2011).
} 


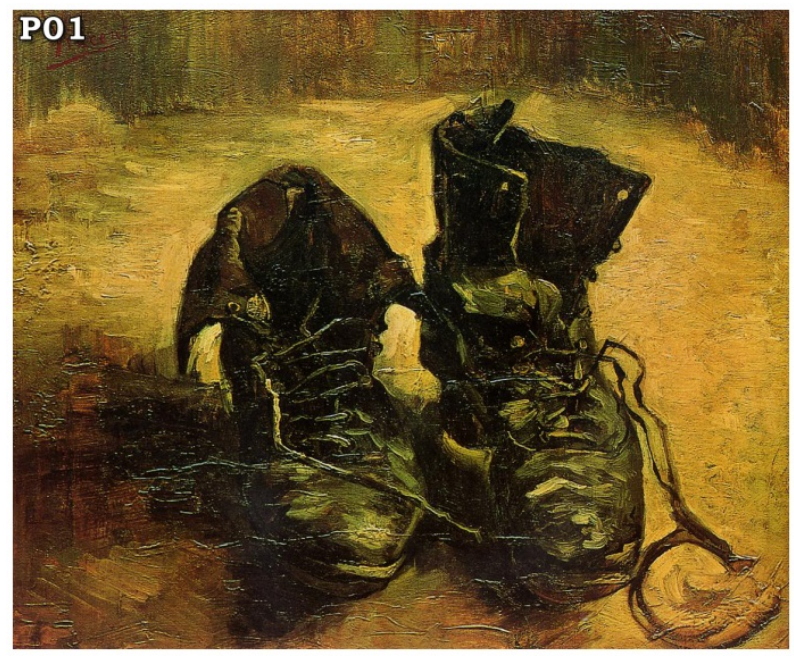

P01: Van Gogh

Os sapatos, pintados em massas de tinta por Van Gogh, com poderosas e decididas pinceladas, se coloca enigmaticamente diante daquele que contempla a obra. Heidegger nos mostra, progressivamente, que as descrições que podemos realizar dos sapatos como utensílios em nada nos ajudam para sabermos do objeto ou da pintura, muito menos para nos fazer avançar para dentro da obra. Ela não possui essa finalidade, muito menos a cumpre. O que os sapatos fazem é nos deslocar, mas para onde? Heidegger nos diz que os sapatos falam poeticamente ao homem que os contempla. As massas colóricas $^{33}$ colocam em obra um estado de abertura, de disposição visual no qual sujeito da contemplação e obra se encontram juntos em um sendo, o qual se constitui em um jogo de presenças. Enquanto a pintura expressa algo, seu observador se sustém nesse algo de forma não determinada, mas simplesmente disposto diante dela. Heidegger identificou esse estado como uma abertura (a aletheia dos antigos gregos) para o ser do pôr da obra que pode ser reconhecido no permanecer diante dela. E não é justamente o que fazemos diante de uma obra de arte? Diante dela, nós nos dispomos, nos despojamos de nosso eu provisoriamente e, ali diante dela, no espaço do encontro com ela, permanecemos em silêncio, demoradamente. Por um tempo somos com a obra.

\subsection{RETROCEDENDO AO CONTEXTO DA PRODUÇÃO DA IMAGEM}

Disposta ao olhar, a imagem é o que, sempre em um arranjo complexo, se dá ao ver do sujeito. Entretanto, se retrocedermos historicamente para aquém do

\footnotetext{
${ }^{33} \mathrm{O}$ uso dos termos colóricas e, posteriormente, colórico, implicam uma flexão do termo cor: impressão que a luz difundida ou transmitida pelos corpos produz no órgão da visão do sistema perceptivo. O termo não é dicionarizado pelo Houaiss, nem pelo Dicionário de Língua Portuguesa.
} 
momento privilegiado da relação entre imagem e seu espectador, adentraremos nos domínios reservados da produção da imagem. Nesse domínio, é que encontraremos o acontecer vivo das ações do fazer-pensar que pulsam nos artífices das imagens. No mundo dos games, esse domínio é o da produção/criação da imagem, situado pelos pesquisadores dentro da chamada etapa de desenvolvimento.

O processo do desenvolvimento da imagem digital dialoga também com o processo da pintura em óleo. Um refinado exemplo desse diálogo entre suportes e processos nos é dado pelo trabalho realizado pelo pesquisador de games e artista plástico Antônio Vargas, em sua série de trabalhos sobre o grotesco ${ }^{34}$. Uma delas é a tela Jerusalém (2007) [P02], formada por um díptico, em um óleo sobre tela (dim. 4,27 x 6,89ft).
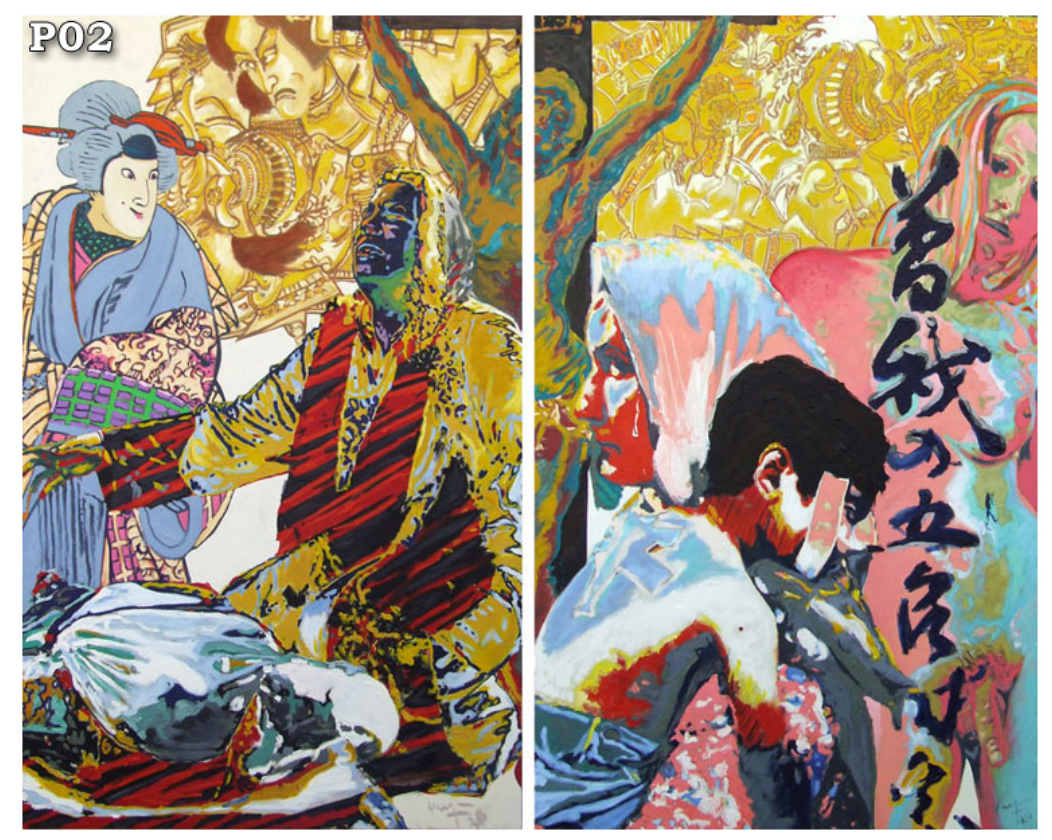

P02: Tela Jerusalém

O trabalho de Jerusalém é apresentado em pintura, mas o processo de sua gestação envolve o trabalho cooperativo entre o digital e a pintura em óleo em um mesmo artífice, coisa que somente se torna possível quando o artista é capaz de transitar com exímio rigor por entre ambos os mundos técnicos. A partir de imagens digitais ou digitalizadas são trabalhadas em um editor de

\footnotetext{
${ }^{34}$ A série de pinturas sobre o grotesco de Vargas, que estão digitalizadas no site de pesquisa Casthalia, podem ser conhecidas em: http://www.casthalia.com.br/vargas/painting.htm. Aqui não consideramos os processos simbólicos e de conteúdo da obra de Vargas, mas sim objetivamos trazer à luz o dialógico que o artífice realiza entre o digital e a pintura em óleo. Para uma análise da obra de Vargas, recomendamos o artigo escrito por Mesquita (2008).
} 
imagens como fragmentos e camadas. Elas são cortadas, fundidas, mescladas e processadas dos mais diversos modos, como filtros de opacidade, contraste, entre outros, e organizadas em uma composição temática pelo artífice digital. Impressa por plotagem em uma superfície e, afixadas em um bastidor, a tela resultante é então objeto-suporte que é disposta ao trabalho do artífice do óleo que, com tinta e pincel dialoga cromaticamente com o digital na produção de uma legítima peça transmídia (Costa, 2012). Como uma espécie de bloco mágico complexo, a tela produz indicações semióticas ao artífice, tais como o fizeram anteriormente os aparelhos de Alberti (1404-1472), Leonardo (14521519), Dürer (1471-1528), Holbein (1497-1543), Van Gogh e outros ${ }^{35}$. No entanto, o tratamento e intimidade com a cor e o traço exercido em tinta com o pincel são aqui os caracteres expressivos e existenciais da pintura que emerge, lenta e demoradamente, nas sessões noturnas de trabalho, nas quais o fazer-pensar recolhe da memória abdutiva a potência da angústia com a qual cada uma das imagens-fragmento o assolava.

O processo descrito de cooperação entre o digital e a pintura em óleo pode nos ajudar a compreender melhor os processos de criação da imagem digital nos games. Ele aparece quando pesquisamos os modos de produção em games utilizados pelas equipes de artistas dos estúdios de desenvolvimento. No nosso caso, iremos enfocar o trabalho de duas equipes de artistas de dois estúdios de desenvolvimento, em dois vídeos que apresentam os trabalhos das equipes e como elas o problematizam.

\section{OS MUNDOS PLÁSTICOS E COLÓRICOS COMO EXPANSÃO DO SER DO JOGO}

Os games podem ser definidos e apresentados de diversas maneiras: como estruturas teatrais computacionais (Laurel, 1993), como objetos evocativos (Turkle, 1984), como narrativas interativas (Murray, 2003), como mundos tridimensionais navegáveis (Manovich, 2005) e assim por diante. Os games são objetos digitais capazes de receber as mais diversas designações, dependendo do enfoque, perspectiva e visada que tenhamos sobre eles. Ora, no presente artigo, inspirados pelos aspectos modular e multiforme desse objeto digital, nos propomos a pensar o game enquanto um objeto da produção artística, orientado por um fazer-pensar que se embasa

\footnotetext{
${ }^{35}$ Cf. o relato que nos fornece Edwards (2004: 122-123).
} 
ontologicamente e que culmina naquilo que temos nos écrans dos computadores e consoles: uma imagem digital ${ }^{36}$.

No plano da imagem digital, nos games, um de seus elementos fundamentais consiste nas estruturas de iluminação que estão em ação na cena, a qual é atualizada na tela como imagem. Como a cor de cada um dos inúmeros objetos que compõem a cena é produzida pela impressão da luz, difundida ou transmitida neles, incide em nossa visão, cor e luz se tornam dos dois elementos coetâneos da produção da imagem artística. Tanto uma como outro possuem suas implicações diegéticas. Ora, um dos aspectos práticos da iluminação em um game corresponde ao conectar e situar o jogador no plano do clima emocional do mundo e da narrativa que está sendo desenvolvida. $\mathrm{Na}$ história da arte, o modo particular de iluminar uma cena configurava o modo como o artista pretendia que ela fosse recebida na pintura. Começando com Leonardo, a luz (e sua correspondente sobra) possui seu marco fundamental com o desenvolvimento da técnica do chiaroscuro ${ }^{37}$ (luz e sombra), necessitando de um profundo conhecimento das várias teorias da perspectiva, das tintas e de suas fusões, o chiaroscuro cuida da representação da incidência da luz e sombra sobre os objetos, nos quais prescindimos a delimitação de seus contornos. Em Rembrandt e Caravaggio (1573-1610), por exemplo, ela produz representações altamente subjetivas na pintura e, muitas vezes, criando diferentes pontos de perspectiva e emissão da luz.

Assim a iluminação ou a luz em si se constituem em um elemento de alto incremento nos atuais desenvolvimentos de jogos ${ }^{38}$. Ela permite 0 estabelecimento da tonalidade emocional e narrativa no ambiente do game, o qual implica fortes conexões com os aspectos diegéticos da imagem.

\footnotetext{
${ }^{36}$ Uma definição muito simplista da imagem digital nos diz que ela consiste na representação computacional de uma imagem bidimensional, a partir de informações numéricas (no sentido francês) ou binárias (no sentido inglês), em uma tela de computador. Para os fins práticos do presente artigo, iremos tomar a ideia de imagem digital, como aquela imagem produzida ou digitalizada que é trabalhada em softwares de pintura (edição de imagens), renderização tridimensional e nos motores de jogos. Sobre o conceito de imagem digital ver, por exemplo, o artigo de Scuri, A. E. (2002). Fundamentos da imagem digital. Rio de Janeiro. Techgraph/PUC-Rio. Disponível em: http://www.tecgraf.puc-rio.br/ scuri/download/fid.pdf. Acesso em 16/-7/2013; ${ }^{37}$ O termo chiaoscuro, do italiano, que significa claro-escuro e, em um contexto atual designa o aprendizado e domínio de se produzir imagens (digitais ou não) utilizando-se desse recurso. Associado a essa técnica, está o sfumato, o qual consiste, em desenho e pintura, em que se cuida dos gradientes perfeitos das cores e superfícies dos objetos.

${ }^{38}$ Ainda que a iluminação sempre fosse considerada um tópico da maior importância na produção de imagens tridimensionais, somente mais recentemente, em virtude do incremento dos processadores em CPUs e Placas de Vídeo é que os desenvolvedores e motores de jogos puderam tirar um mais considerável partido dela.
} 


\subsection{A LUZ COMO UM AGENTE DIEgÉtICO DO MUNDO DO GAME: O LIGHT DESIGN}

Como observado, a imagem digital iluminada, particularmente, carrega um sentido especial nos games. Sentimentos, sensações, aspectos cognitivos e a caracterização geral do mundo, bem como o estado emocional das personagens podem ser transmitidos pelo trabalho de iluminação em uma cena tridimensional, a qual nos é oferecida como uma imagem (sempre em constante estado de transformação). A partir desse contexto, surge o conceito de light design ${ }^{39}$ nos games, o qual foi desenvolvido por Ian Milham e sua equipe, para o desenvolvimento de Dead Space 2 (Visceral Games, 2011). O conceito de light design compreende um planejamento completo prévio da luz/iluminação dentro jogo e, no seu desenvolvimento, a alocação de uma equipe especializada e dedicada a ele ${ }^{40}$.

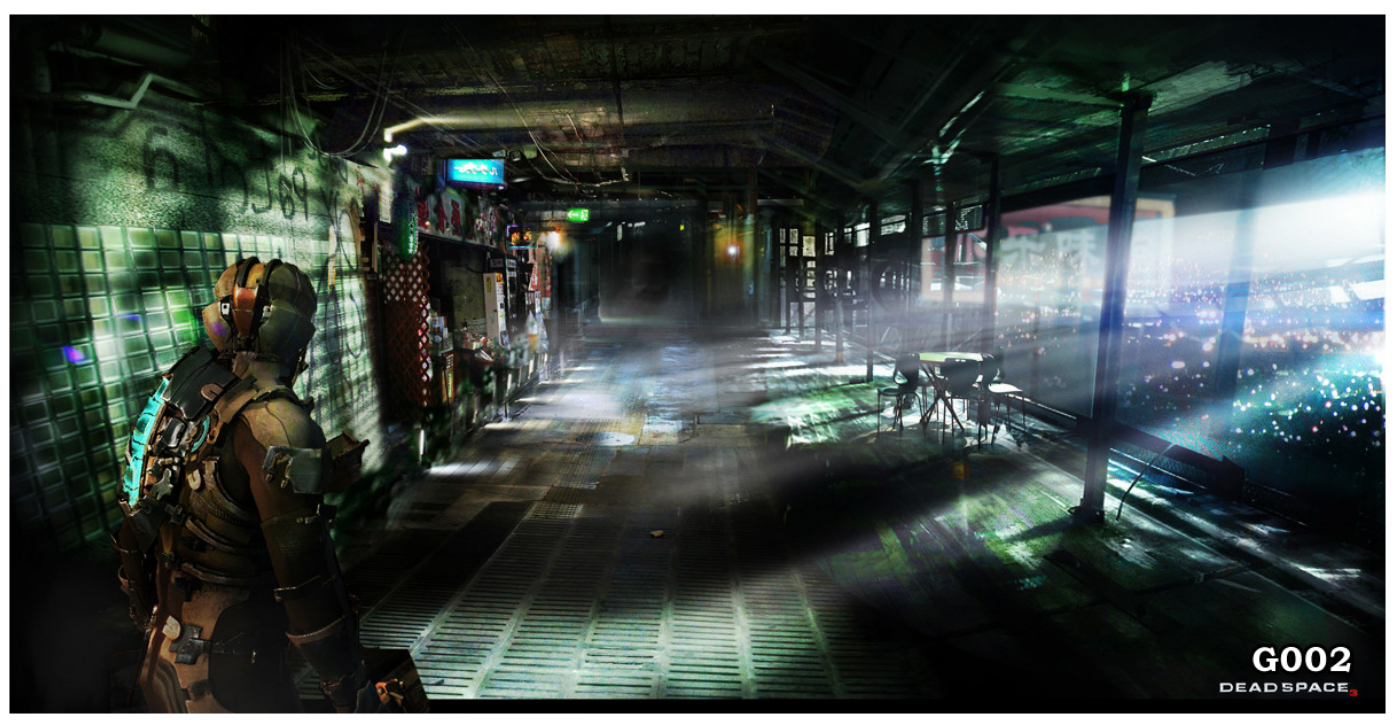

G02: Dead Space 2

Milham (LDS2, 0:30), diretor de arte do Dead Space 2, nos informa que a iluminação permitiu a criação de uma atmosfera crível e de terror no game. Sua importância é tal que ela é tratada como uma personagem: possui comportamentos que são próprios e planejados dentro do light design. É nesse

\footnotetext{
${ }^{39} \mathrm{O}$ termo light design poderia ser traduzido para o português como design de luz ou design de iluminação. Como o termo design foi dicionarizado na língua portuguesa ele permanece, trazendo os significados de método, configuração física, plano, projeto, criação. Mais remotamente o termo remonta ao disegno, do italiano. No presente artigo iremos manter o uso do termo na sua acepção inglesa: light design.

${ }^{40}$ Informações valiosas sobre o processo de light design no game são fornecidas no vídeo The Lighting \& Atmosphere of Dead Space 2 Developer Diary: The horrific atmosphere of Dead Space 2 (Visceral Games, 2011), ao qual iremos nos reportar como LDS2 nas referências a minutagem no texto, exemplo: (LDS2. 0:40). Ian Milham, art director e Rachel Cross, senior lighting artist, falam no vídeo explicando o conceito de light design e como ele foi usado no game.
} 
sentido que a luz, dentro do game, nos remete a uma atmosfera (do mesmo modo como em um filme), a partir da qual o jogador é colocado dentro do clima requerido para a narrativa. Muitas são as situações nas quais a luz fala (é o agente, o main character) no game como um de suas personagens centrais. Ao observamos a imagem do game, podemos perceber que é justamente ela que indica o próprio da cena, onde o sentimento terrífico é dado, não pela escuridão, mas pela estrutura de trabalho da luz.

Portanto, toda a ambientação de um jogo digital, assim como a de um filme, nos fornece pistas da condição do protagonista. No caso de Dead Space 2, temos constante presença de fumaça e névoa em inúmeros ambientes, nos remetendo ao próprio estado de confusão mental de Isaac Clark, protagonista do jogo, que saiu recentemente de um sanatório.

Contudo, para poderem chegar até esse ponto, os artistas do game precisaram também recorrer aos conhecimentos e inspirações guardados na história da arte, buscando na história do chiaroscuro contribuições fundamentais. Milham (LDS2, 3:35) nos diz que encontraram nos trabalhos de Rembrandt ideias fundamentais para a formação da identidade visual no que dizia respeito, dentre outras características, à iluminação, dentro da qual, não é a falta de luz que produzia o ambiente terrífico, mas a sua presença pensada.

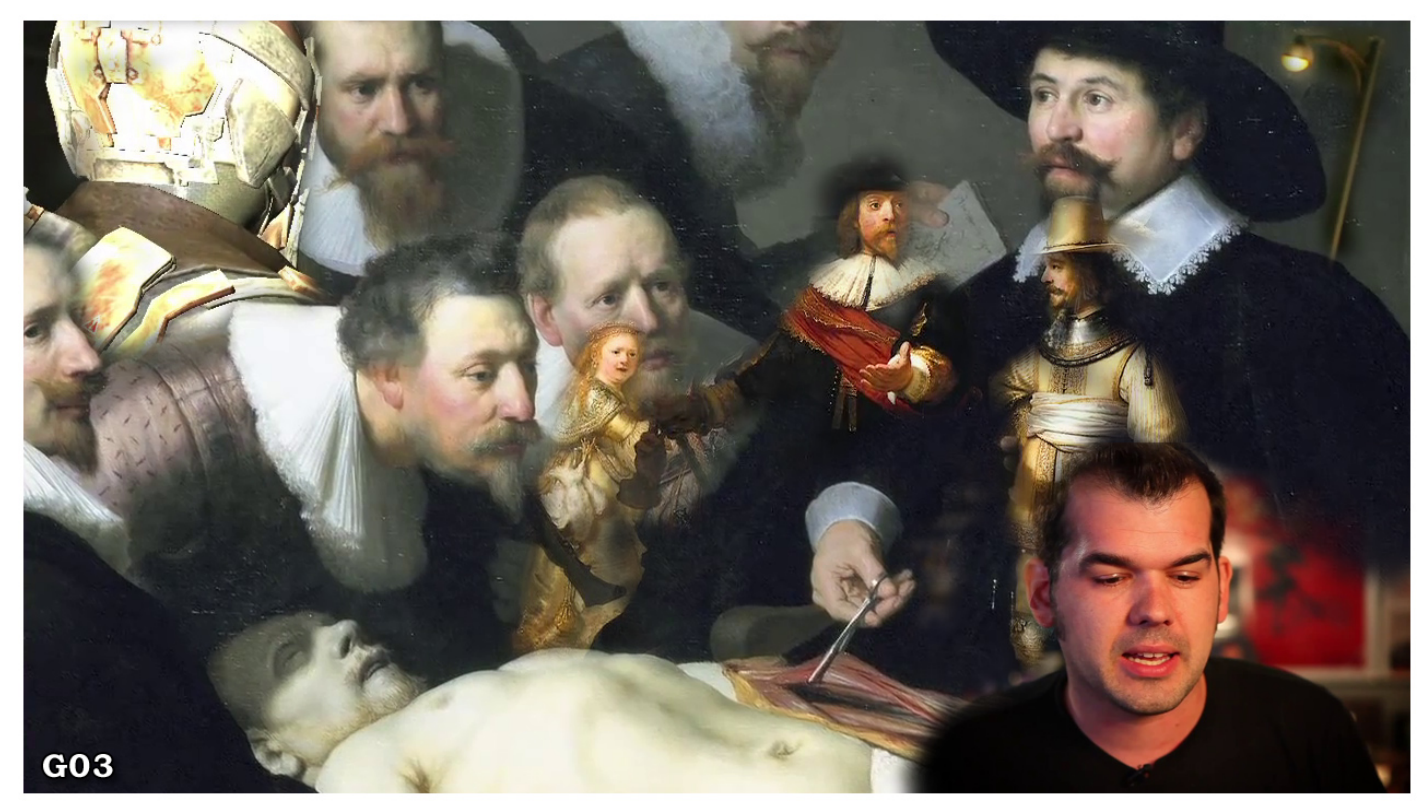

G03

As ideias aprendidas e expressas pela equipe de DS2 serão seguidas por outras, incorporando-se a padrões de qualidade que irão inspirar outros produtores, assim como Rembrandt foi inspiração para eles. 


\subsection{A COR E A PINTURA COMO ELEMENTOS GUIA DO JOGO}

Nosso objeto e análise final se concentrarão na apresentação de uma situação que parte das ideias do light design e focaliza os seus esforços na produção de imagens de jogo que estão referenciadas a pinturas digitais realizadas como concept $a \mathrm{rt}^{41}$. Ele surge nos relatos de produção do game The Last of Us $(2013)^{42}$ que igualmente foram registrados em uma série de vídeos de relatos de produção, que buscam promover o game junto aos fãs e comprovar a qualidade do trabalho e da equipe envolvida.

A equipe de do estúdio Naughty Dog publicou no canal da Sony no YouTube, uma série de vídeos, intitulados The Last of Us Development Series (Naughty Dog, 2013). O segundo deles tem como subtítulo a expressão Wasteland Beautiful $^{43}$, no qual a equipe de desenvolvimento oferecem depoimentos acerca dos aspectos considerados para a criação dos ambientes, expondo aspectos do método criativo, seu processo de produção e enfocando a produção dos concept arts, que irão regular todo o trabalho posterior de desenvolvimento.

\footnotetext{
${ }^{41} \mathrm{O}$ termo concept art pode ser traduzido como arte de conceito. Ainda não dispomos de uma adequada tradução para ele, entretanto ele possui forte vinculação com os estudos que foram realizados pelos artistas, em partes e aspectos, visando a uma composição final, como é o caso de muitos esboços de Leonardo, Dürer e outros na história da arte.

${ }^{42}$ De acordo com o colocado pela Naughty Dog no site do game, em sua essência, The Last of Us é um jogo que trata do vínculo que se forma entre os dois personagens principais, Joel controlado pelo jogador e Ellie, na base de IA: a experiência construída pelos autores nos leva a uma história de amor, lealdade e redenção.

${ }^{43}$ Ao qual iremos nos reportar como WB nas referências a minutagem no texto: (WB, 0:50), por exemplo. Realizam depoimentos no vídeo Wasteland Beautiful (WB), Neil Druckman: creative director; Phillip Kovats: audio lead; Bruce Straley: game director; Nate Wells: lead artist; Adelle Bueno: environment artist; John Sweeney: concept artist; Travis Mcintosh: lead programmer; Aaron Limonick: concept artist; Erick Pangilihan: art director; Vivian Ding: lead lighting artist; Leandro Amaral: lighting artist e Michal Iwanicki: graphics programmer. Uma excelente galeria de imagens vista em: http://www.thelastofus.com/media.html\#screenshots.
} 

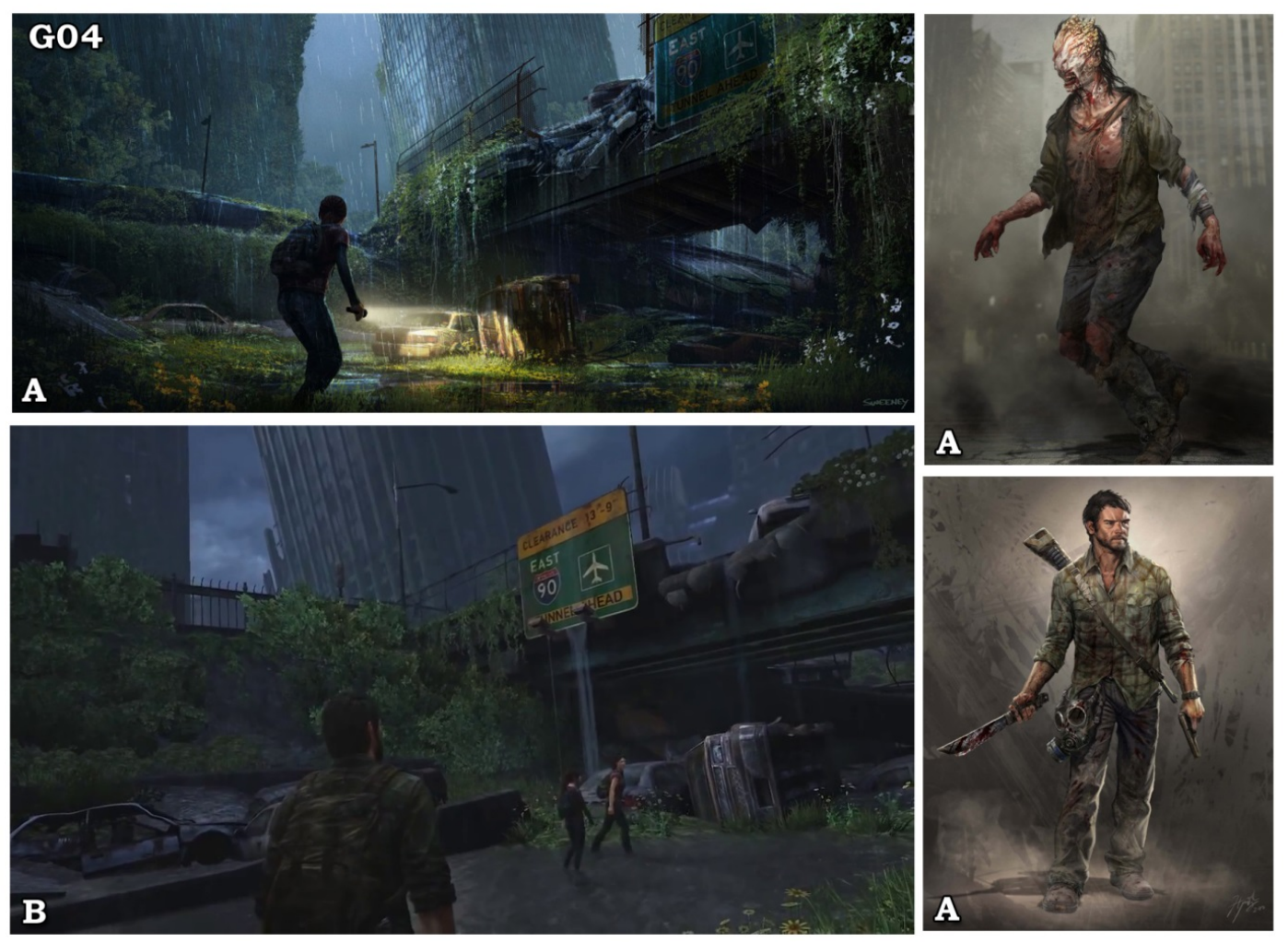

G04

Segundo Kovats (WB, 0:50), os cenários foram tratados como uma personagem de grande destaque no jogo. Eles foram desenhados/pintados [G04 A] e estão atuando no plano da narrativa, juntamente com as personagens e o jogador. Importava sobremaneira como esses ambientes que constituíam os cenários fossem percebidos pelo jogador. Estamos no game em um mundo pós-cataclísmico que é pensado como uma Wasteland, na qual a mãe natureza começa a reclamar seu espaço de volta. A beleza das texturas urbanas é invadida e tomada, pouco a pouco, em vinte anos, pela beleza natural.

Para a equipe de arte do game, importava definir claramente quais as características da personalidade daqueles ambientes para que, além de abrigar a ação do jogo, pudessem sensibilizar os jogadores e assim colaborar na narrativa do jogo, trazendo para o primeiro plano, não só a atmosfera e o background do jogo, mas contando por si só uma história. Dessa forma, a paisagem como elemento semiótico, de forma indireta, visava reforçar a imersão do jogador dentro da trama por meio da sinestesia, ou seja, a narrativa, além de ser construída com diálogos muito bem equilibrados e cutscenes, utiliza-se da telepresença (Manovich, 2001) de características estéticoartísticas primorosas, a qual é vivida pelos jogadores em sua percepção 
espacial emulada, para compor as percepções e emoções vividas por eles e passá-las ao jogador.
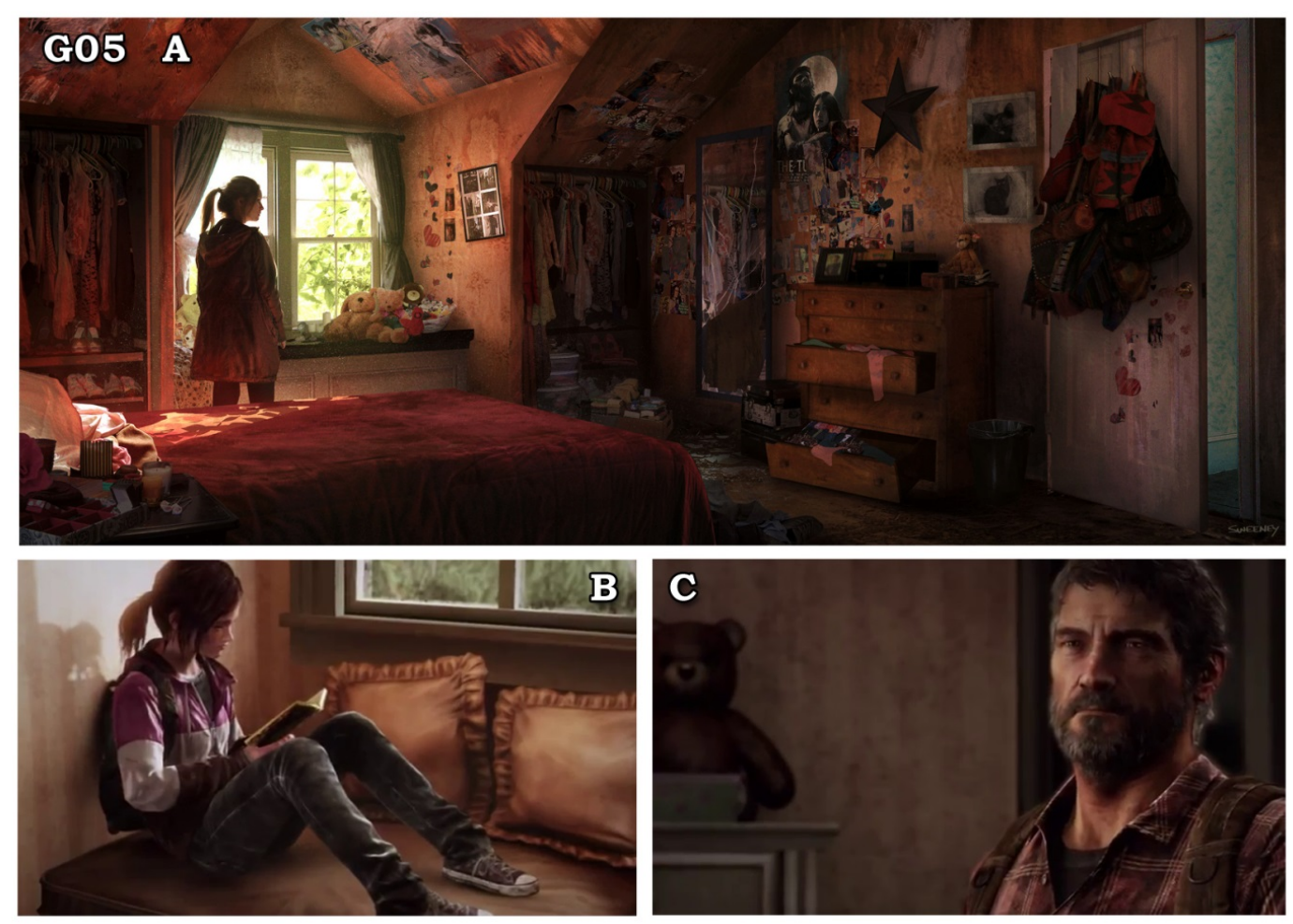

G05

Para alcançar o feito de transformar o ambiente em uma personagem, capaz de por si só articular uma narrativa, seria necessário o processo para se trazer à luz uma segunda realidade (Gombrich, 2007). Conforme é dito por membros da equipe junto com Pangilihan (WB, 3:31): a iluminação foi pensada desde o início (tal como o visto em DS2), na sensibilidade presente na luz (WB, 3:37), em seu poder de transformar a apreensão do ambiente, conhecimento esse dominado pelos pintores. Nesse ponto, a equipe de técnicos e artistas da Naughty Dog caminha, pari passo, com a fenomenologia (Heidegger, 2010), quando esta nos mostra que para chegarmos ao de habitar um dado espaço do mundo, temos de passar pelo construir, ou seja, para que a imagem, ou espaço seja sólido o suficiente, para que possa ser habitado por seus observadores, deve ter sido construído de forma pensada, pois somente assim a criação poderá abrigar o olhar e ser passível de ser habitada (Petry, 2009). Mas a referência estética a ser seguida aqui, tanto para as pinturas de concept art, como para o ambiente em execução no jogo, que toma aquelas como sua referência absoluta, não é o realismo fotográfico, de modo algum. No game, nós temos como parâmetro de produção uma estética de cunho impressionista. 
Em muitos momentos, temos a impressão de estarmos dentro de uma pintura em tempo real (sendo executada pelo motor de jogo).

No processo de produção de um jogo, o raciocínio de se construir os ambientes é utilizado de forma procedimental, tal como nos é apresentado no vídeodocumentário Wasteland Beautiful ${ }^{44}$. Esse processo de construção inicia-se com a elaboração das concept arts [G04 A e G05 A]. Elas são as responsáveis por definir as características estéticas principais que o jogo acabado terá (Novak, 2010), ou seja, as imagens elaboradas a partir de um conceito inicial além de se colocarem como o primeiro passo da produção, fazem-se presentes em todas as etapas de produção, como referencia para o ajuste do game como pode ser observado em [G04 B e G05 B e C].

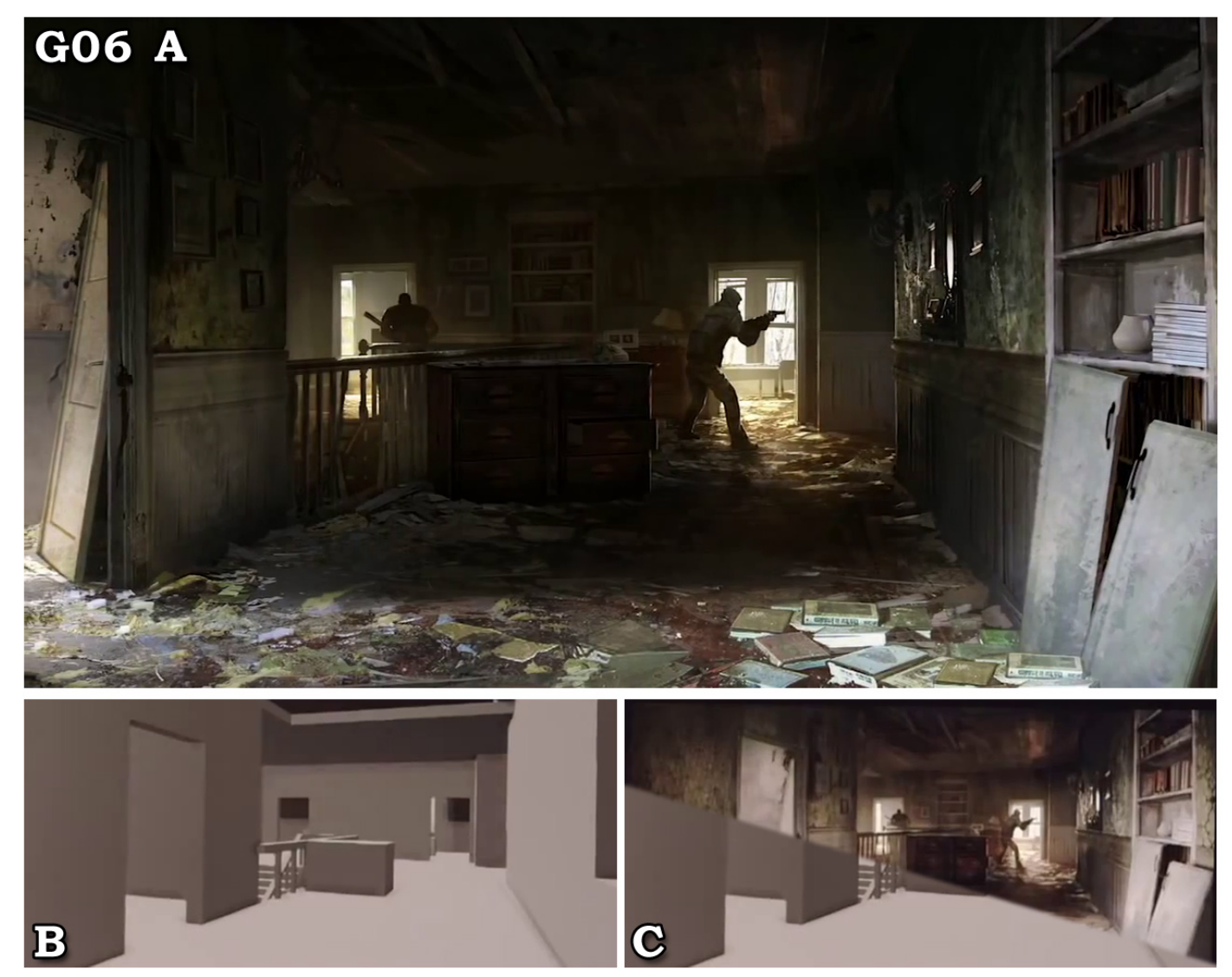

G06

Para a produção de Last of Us, o início do processo não foi diferente, primeiro foram elaborados os concept arts iniciais [G04 A, G05A e G06 A], após a delimitação da tonalidade estética do game ser definida, iniciaram-se os trabalhos de game design e de projeto de arquitetura de nível, em que são

\footnotetext{
${ }^{44} \mathrm{E}$ igualmente em diversos outros relatos da indústria e livros como por exemplo, relatado por Novak (2011), em seu livro Desenvolvimento de games.
} 
definidos os locais por onde as personagens poderão caminhar, onde existirão obstáculos e eventos do jogo, ou seja, a construção do ambiente digital de forma interativa. O projeto de arquitetura de nível passa para uma equipe de modeladores que transforma os desenhos parametrizados, desenhos feitos com o intuito de cobrir os ângulos e visões necessários para o entendimento do projeto e sua modelagem, elaborados na etapa anterior de projeto de arquitetura de nível, em um modelo tridimensional sem texturas ou detalhes, conforme pode ser visualizado no vídeo (WB, 1:43) [G06 B], no qual Sweeny, um dos concept artists, utilizando essa modelagem de base para elaboração de uma perspectiva, mostra a próxima etapa do trabalho, a criação de uma arte conceitual que visa detalhar o game, fornecendo-lhe vida e um caráter único e cristalino ao ambiente, mostrado na correlação de imagens em [G06 C]. Após essa etapa, o modelo tridimensional do nível passa pelas modificações necessárias para que fique semelhante ao concept art destinada a ele, trabalhando-se principalmente os requisitos de texturas e iluminação. Como podemos observar, a imagem artística é o guia e a referência a ser seguida.

Ora, é nesse sentido que Bueno (WB, 1:37), uma das environment artist de Last of Us nos diz: cada nível possui uma equipe de especialistas nas áreas de nível, iluminação e textura trabalhando juntos, ou seja, é necessária uma equipe completa para trazer à luz essa segunda realidade, de forma que esta possua não só as qualidades práticas de um local a ser utilizado, a sua funcionalidade, mas também as qualidades estéticas perseguidas pela equipe de desenvolvimento, que possibilitem, inclusive, de contar uma história, criando assim sua própria dimensão semiótica, proporcionando inúmeros sentidos àquele mundo que teve seu início com desenhos e pinturas conceituais (Bateman, 2013).

Nesse sentido, é que encontramos aqui a exposição da presença marcante do artífice no processo do fazer-pensar que ocupa completamente o plano da imagem digital no desenvolvimento do game. A configuração do game para com a pintura do concept art conduz ao permanente estado da homoiosis aristotélica, na qual o desenvolvimento visa à produção de uma experiência estética em que o caráter da pintura (impressionista) se coloca como ser mais íntimo do jogo: o homem está condenado a ser tragado pela beleza de um mundo devastado. 


\section{CONCLUSÃO: A IMAGEM DIGITAL COMO NARRATIVA NA ABERTURA DE MUNDO}

Quando pensamos nas narrativas nos games, encontramos neles uma forte vocação transmídia (Jenkins, 2009), com a capacidade de fazer uma narrativa migrar por entre muitos meios e formas, associada à potência diegética dos ambientes tridimensionais imersivos. Será nessa perspectiva, que poderemos identificar o colocado por Murray (2003), quando nos diz que o desejo ancestral de viver uma fantasia originada num universo ficcional foi intensificado por um meio participativo e imersivo, que promete satisfazê-lo de um modo mais completo do que jamais foi possível. É nesse sentido, que, ao jogar um jogo (digital), o jogador é lançado em um ambiente digital, tendo o seu contexto háptico, sinestésico, sensorial e cognitivo potencializado e plasmado em imagens e sons. O trabalho do nosso artífice labora no sentido de potencializar essa perspectiva: se os quadros falam, como diz Heidegger (2010), pensamos que os games também podem falar ao mais íntimo do homem como obras de arte.

A toda narrativa antecede um mundo, um universo plástico e ôntico (Petry, 2003). O pensamento significa que o ambiente antecede a narrativa e vêmo-lo presente nos desenhos e pinturas digitais que organizam os concept arts. Vêmo-lo, igualmente, nos protótipos e no céu a descoberto do mundo do jogo que demanda ser jogado. A narrativa acontecerá nesse mundo apoderando-se dos sentidos do mundo para ser construída. Isso significa que o mundo precisa estar lá, ou seja, ele se constitui em uma estrutura prévia a toda e qualquer narrativa. Seja ele concreto, uma imagem mental, ou uma representação digital, haverá a necessidade de algo que evoque os signos para a construção narrativa e esse algo pode ser encontrado no mundo digital que the serve de substrato. É nesse sentido que o mundo como um todo (incluindo aqui os seus objetos) se constituem nas estruturas interativas providas de sentido.

Apresentamos aqui uma formalização que nos indica que o artista digital dos games pode ser um sujeito que, ao mesmo tempo em que trabalha com suas mãos, pensa com seu cérebro e sente com seu coração - um artífice que subsome na atividade da poièsis. De sua atividade de produção de imagens multicores, pudemos constatar o florescimento de uma diegese circundante e não menos importante. Observamos que o processo do trabalho no atelier da produção da imagem digital pode ficar soterrado (como processo do fazer pensante) na beleza apresentativa da imagem e, ao realizarmos a indicação da existência de um claro processo reflexivo presente nas equipes de 
desenvolvimento de game, como nos casos modelares, apresentados nos vídeo LDS2 e WB, mostramos a validade de nossas premissas: os artífices digitais dos games pensam profundamente o objeto e sentido de seu trabalho; seu pensar se suporta por uma ontologia (ainda que, na maior parte das vezes, atencionada); que a adequação do produto resultante alcança o mais alto grau de significância quando ele é guiado pela busca da qualidade impressa no fazer do artista, condição base para a germinação de uma autêntica narrativa.

Com o presente artigo, objeto de uma discussão dentro de um grupo de pesquisa em games, não pretendemos colocar uma palavra final na questão aberta. Queremos, sim, lançar e partilhar as interrogações que nos assolam e, na certeza de que o traço deve ser contado, mesmo depois do círculo concluído e mostrado, é que ficamos maravilhados quando os games, de diversos tipos, tonalidades, gêneros e estilos, podem ser produzidos com o carinho e o rigor que merecem uma obra de arte, pensando no que nos indicou Gadamer (1998), em Verdade e método: arte e verdade são inseparáveis.

\begin{abstract}
Wasteland Beautiful: o estatuto ontológico da imagem nos mundos tridimensionais dos games é um texto produzido por Luís Carlos Petry, Thiago Sanches Costa, Alexandre Vieira, Gabriel Marques e Marcel Casarini, pesquisadores do NuPHG, Núcleo de Pesquisas em Hipermídia e Games da PUCSP. Departamento de Ciência da Computação e Programa de Pós-graduação em Tecnologias da Inteligência e Design Digital.
\end{abstract}

\title{
REFERÊNCIAS
}

AUMONT, J. (2005). A imagem. Campinas. Papirus.

BATEMAN, C. (2011). Imaginary games. Winchester UK. Zero Books.

BELLETÊTE, J. J. (2011). Deus Ex Human Revolution Design Work. Montréal. SQUARE ENIX. AINSI

BOBANY, A. (2007). Video Game Art. Teresópolis. Novas Ideias.

BRUNO, S. (2011). Coleção Grandes Mestres: Rembrandt. São Paulo. Abril S.A.

COSTA, T.S. (2012). O Salto Transmidiático dos Super-Heróis. São Paulo. Dissertação de mestrado defendida no PPG Tecnologias da Inteligência e Design Digital - PUCSP. Orientador: Luís Carlos Petry 
CRUZ, J. L. (2007). Pintura e cinema: anotações para uma primeira reflexão. In: Anais do $16^{\circ}$ Encontro Nacional da Associação Nacional de Pesquisadores de Artes Plásticas. Florianópolis. ANAP. Disponível em: <http://www.anpap.org.br/anais/2007/2007/artigos/141.pdf>

EBERT, R. (2010). Video games can never be art. In: Blog RogerEbert.com. 16/04/2010. EUA. Ebert Digital LLC. Disponível em: <http://www.rogerebert.com/rogers-journal/video-games-can-never-be-art> Acesso em: 16/-7/2013

ECO. U. (2000). Tratado geral de semiótica. São Paulo. Perspectiva.

EDWARDS, B. (2004). Desenhando com o lado direito do cérebro. São Paulo. Ediouro.

FOX, J. \& Sharp, J (2009). Making Games Art: The Designers' Manifesto. In: GAMASUTRA: The art \& busines of making games. EUA. UBM Technology, a division of United Business Media LLC. Disponível em: <http://www.gamasutra.com/view/feature/132366/making_games_art_the_de signers_.php> Acesso em: 15/07/2013.

FUNK, J. (2011). Games now legally considered an art form (in the USA). In: The Escapist. EUA. Alloy Digital, LLC. Disponível em: <http://www.escapistmagazine.com/news/view/109835-Games-Now-LegallyConsidered-an-Art-Form-in-the-USA\#50TJRztFI7ZYMJ0h.99> Acesso em: $16 / 07 / 2013$.

GIBSON, W. (2013). Neuromancer. São Paulo. Aleph. ISBN: 9788576570493;

GIBSON, W. (2013). Count Zero. São Paulo. Aleph. ISBN: 9788576570509;

GIBSON, W. (2013). Monalisa Overdrive. São Paulo. Aleph. ISBN: 9788576570516 ;

GAMEFREAKS. (2013). The Last of Us artwork reveals apocalyptic world. In: Blog GAMEFREAKS Ltd. New Zeland. NZ Videogame news, reviews and trailers. Disponível em: <http://www.gamefreaks.co.nz/2013/06/18/last-artworkreveals-apocalyptic-world/> Acesso em: 14/07/2013;

GOMBRICH, E. H. (2007). Arte e ilusão. Um estudo da psicologia da representação pictórica. São Paulo. Martins Fontes. 
GOODMAN, N. (2006). Linguagens da arte. Uma abordagem a uma teoria dos símbolos. Lisboa. Gradiva.

HAZIOT, D. (2010). Van Gogh. Porto Alegre. L\&PM.

HEIDEGGER, M. (1974). A proveniência da arte e a determinação do pensar. Disponível em <http://personales.ciudad.com.ar/M_Heidegger/index.htm> Acesso em: 05/10/2008;

HEIDEgGeR, M. (2008). Observações sobre Arte - Escultura - Espaço. Artefilosofia no 5. Ouro Preto. Disponível em: http://www.raf.ifac.ufop.br/sumarios-n5.html. Acesso em: 15/07/2013. ISSN: 18098274 ;

HEIDEgGeR, M. (2009). Remarques sur art - sculpture - espace. Paris. Éditions Payot \& Rivages.

HEIDEGgER, M. (2010). A origem da obra de arte. São Paulo. Edições 70.

HEIDEGGER, M. (2012). Ensaios e Conferências. Petrópolis. Vozes.

JENKINS, H. (2006). Cultura da Convergência. São Paulo. Aleph.

KANDINSKY, W. (2001). Ponto e linha sobre plano. São Paulo. Martins Fontes.

KEMP, M. (2004). Leonardo da Vinci. Rio de Janeiro. Jorge Zahar Editor.

LAUREL, B. (1993). Computer as Theater. EUA. Addison-Wesley Professional.

MANOVICH, L. (2005). El lenguaje de los nuevos medios de comunicación: la imagen em la era digital. Buenos Aires. Paidós.

MESQUITA, A. (2008). Improbable visions of a remixed painting. Site Casthalia. Florianópolis. Disponível em: <http://www.casthalia.com.br/vargas/imagensvargas/pintura_remix.pdf> Acesso em: 16/07/2013;

MURRAY J. (2003). Hamlet no holodeck: o futuro da narrativa no ciberespaço. São Paulo. Itaú Cultural, Unesp.

NAUGHTY DOG. (2013). The Last of Us: Survival edition. [Playstation3 game]. EUA: Sony. Disponível em: <http://thelastofus.com/> Acesso em: 15/07/2013. EAN: 711719991830; 
NAUGHTY DOG. (2013). The Last of Us Development Series Episode 2: Wasteland Beautiful. [Playstation3 game]. EUA: Sony. Disponível em: <http://www.youtube.com/watch?v=-ZJ2C6wAVpg> Acesso em: 15/07/2013;

PARDEW, L. (2004). Begining Illustration and Storyboarding for Games . EUA. Cengage Learning PTR.

PETRY, A. S. (2010). O jogo como condição da autoria e da produção de conhecimento. São Paulo. Tese de Doutorado defendida no PPG Comunicação e Semiótica - PUCSP. Orientadora: Lucia Santaella.

PETRY, L. C. (2003). Topofilosofia: o pensamento tridimensional na hipermídia. São Paulo. Tese de Doutorado defendida no PPG Comunicação e Semiótica PUCSP. Orientador: Sérgio Bairon.

PETRY, L. C. (2009). A im@gem pensa: Aspectos quânticos da imagem cibernética, in CIBERTEXTUALIDADES \#3. Porto / Portugal.

PETRY, L. C. (2011). Fundamentos ontológicos dos metaversos e games. In: Revista de Comunicação e linguagens: gealogias da Web 2.0. No 42. Lisboa. CECL-Relógio d'Água. ISSN: 08707081;

RABIN, S. (2011). Introdução ao Desenvolvimento de Games; Volume 1: Entendendo o Universo dos Jogos. São Paulo. Cengage Learning.

RABIN, S. (2012). Introdução ao Desenvolvimento de Games; Volume 3: Criação e Produção Audiovisual. São Paulo. Cengage Learning.

ROBINSON, M. (2013). The Art of Dead Space. Londres. Titan Books.

SENNETT, R. (2009). O artífice. Rio de Janeiro. Record.

SCHUYTEMA, P. (2008). Design de Games: Uma Abordagem Prática. São Paulo. Cengage Learning.

SCHLÖGL, L. (2011). Bazin e o cinema impuro: uma análise teórica sobre as adaptações no cinema. In:Soc. Bras. de Estudos Interdisciplinares da Comunicação. XII Congresso de Ciências da Comunicação na Região Sul Londrina - PR - 26 a 28 de maio de 2011. Londrina. Intercom. Disponível em: <http://www.intercom.org.br/papers/regionais/sul2011/resumos/R25-01391.pdf. > Acesso em 16/07/2013; 
STONEHAM, B. (2010). How To Create Fantasy Art For Video Games. Londres. Barro's Educational Series.

TUGENDHAT, E. (1992), Wittgesntein: A impossibilidade de uma 'Linguagem Privada'. Porto Alegre. UFGRS. Extraído da Revista do CEBRAP n. 32 de 1992. Disponível em: http://www.cfh.ufsc.br/ wfil/tugendhat.htm. Acesso em: 19/07/2013;

TURKLE, S. (1984). The second Self. Computers and the human spirits. MIT Press.

VISCERAL GAMES. (2011). Dead Space 2. [PlayStation 3, Xbox 360, PC game]. EUA. Eletronic Arts. Disponível em: <http://www.ea.com/dead-space-2> Acesso em 10/07/2013;

VISCERAL GAMES. (2011). The Lighting \& Atmosphere of Dead Space 2 Developer Diary. [PC, Xbox e Playstation3 game]. EUA: Eletronic Arts. Disponível em: <www.youtube.com/watch?v=QVScU2zyoNQ.> Acesso em: 14/07/2013;

YIN, W. (2011). Impeccable Scene Design. Berkeley. Gingko Press. 